\title{
Review of extended-release formulations
} of Tramadol for the management of chronic non-cancer pain: focus on marketed formulations

This article was published in the following Dove Press journal: Journal of Pain Research

24 March 2014

Number of times this article has been viewed

\author{
Arshi Kizilbash' \\ Cường Ngô-Minh² \\ 'Delta Health Services Inc., \\ Mississauga, Ontario, Canada; \\ ${ }^{2}$ Somerset West Community Health \\ Centre, Ottawa, Ontario, Canada
}

Correspondence: Arshi Kizilbash Delta Health Services Inc., 77 City Centre Drive, East Tower Suite 50I, Mississauga, Ontario, L5B IM5, Canada $\mathrm{Tel}+\mathrm{I} 8884074333$

Fax + I 8888009826

Email akizilbash@deltahealthservices.com

\begin{abstract}
Patients with chronic non-malignant pain report impairments of physical, social, and psychological well-being. The goal of pain management should include reducing pain and improving quality of life. Patients with chronic pain require medications that are able to provide adequate pain relief, have minimum dosing intervals to maintain efficacy, and avoid breakthrough pain. Tramadol has proven efficacy and a favourable safety profile. The positive efficacy and safety profile has been demonstrated historically in numerous published clinical studies as well as from post-marketing experience. It is a World Health Organization "Step 2" opioid analgesic that has been shown to be effective, well-tolerated, and valuable, where treatment with strong opioids is not required. A number of extended release formulations of Tramadol are available in Canada and the United States. An optimal extended release Tramadol formulation would be expected to provide consistent pain control with once daily dosing, few sleep interruptions, flexible dosing schedules, and no limitation on taking with meals. Appropriate treatment options should be based on the above proposed attributes. A comparative review of available extended release Tramadol formulations shows that these medications are not equivalent in their pharmacokinetic profile and this may have implications for selecting the optimal therapy for patients with pain syndromes where Tramadol is an appropriate analgesic agent. Differences in pharmacokinetics amongst the formulations may also translate into varied clinical responses in patients. Selection of the appropriate formulation by the health care provider should therefore be based on the patient's chronic pain condition, needs, and lifestyle.
\end{abstract}

Keywords: analgesics, opioids, chronic pain, drug delivery, pharmacokinetics, Tramadol

\section{Introduction}

The two faces of pain

It is useful to distinguish between two basic types of pain; acute and chronic. Acute pain, for the most part, results from disease, inflammation, or injury to tissues. This type of pain generally comes on suddenly, for example, after trauma or surgery, and may be accompanied by anxiety or emotional distress. The cause of acute pain can usually be diagnosed and treated, and the pain is self-limiting - that is, it is confined to a given period of time and severity. In some rare instances, it can become chronic. ${ }^{1}$ Chronic pain is defined as persistent pain, which can be either continuous or recurrent, and of sufficient duration and intensity to adversely affect a patient's well-being, level of function, and quality of life. ${ }^{2}$ A number of definitions of chronic pain have been described in published literature, ranging from persistent pain of at least 2 weeks duration, to continuing for longer than 6 months, to persistent pain that is not amenable to routine pain control methods. ${ }^{3,4}$ Given the debilitating effects of chronic pain and its impact 
on the quality of life, chronic pain is widely viewed by experts to represent a disease itself. It can also be made much worse by environmental and psychological factors. Chronic pain persists over a longer period of time than acute pain and in many cases may be resistant to routine medical treatments. It can and often does cause severe problems for patients. A person may have two or more coexisting chronic pain conditions such as osteoarthritis, rheumatoid arthritis, chronic low back pain, diabetic neuropathic pain, fibromyalgia, endometriosis, Crohn's disease, and ulcerative colitis., ${ }^{3,5}$

\section{Focus on chronic pain}

Pain is an enormous global health problem. Although the burden of chronic pain worldwide is underestimated, it is anticipated that one in five adults suffer from pain and that another one in ten adults (approximately 60 million) are each year diagnosed with chronic pain that falls in the moderate to severe category. ${ }^{6,7}$ Even children are not spared, with $15 \%-30 \%$ of children experiencing recurring or chronic persistent pain. ${ }^{8}$ Pain that interferes with life also increases with age and in those with physically strenuous work or less education. ${ }^{11}$ The prevalence of chronic pain, defined by duration, in the World Health Organization's (WHO) World Mental Health Surveys was 37\% in developed countries and $41 \%$ for developing countries. ${ }^{8}$ In one survey, $19 \%$ of the general adult population of Europe had moderate to severe chronic pain for a median of 7 years and one in five of those had suffered with chronic pain for over 20 years. ${ }^{14}$ Age and sex variations in chronic pain prevalence are remarkably consistent across countries and populations. ${ }^{8}$ In the North American population specifically, it is estimated that between $12 \%-25 \%$ of the population in the United States and between $15 \%-30 \%$ of the Canadian population experiences chronic pain. ${ }^{7,9,10}$ In only about $1 \%-2 \%$ of the population with chronic pain does the pain result from different forms of cancer. ${ }^{6-8}$

Chronic pain impairs everyday activities and quality of life. Psychological morbidities are often observed among patients with chronic pain, which can include depression and suicidal ideations. ${ }^{8}$ Chronic pain also carries a great economic burden. ${ }^{6,12}$ In a recent report from the United States, the estimated annual cost of chronic pain in adults including associated health care expenses and lost productivity was US\$560-630 billion annually. Similarly, the annual cost of chronic pain in Canada, including medical expenses, lost income, and lost productivity is estimated to exceed US\$10 billion annually, not accounting for social costs. ${ }^{7,9}$ The financial cost of chronic pain is estimated to be roughly the same as cancer or cardiovascular diseases..$^{8,13}$
The high prevalence and incidence of global chronic pain, its substantial and growing comorbidities, and its linkage with a myriad of social and economic determinants collectively provide ample justification for regarding pain as a public health priority. Three groups of conditions are large components of the burden of chronic non-cancer pain: osteo- and rheumatoid arthritis, injuries, and spinal problems. ${ }^{13}$ Other causes include headaches, diabetic neuropathies, toxins (eg, alcohol), neurological disorders, stroke, and human immunodeficiency virus infection/acquired immunodeficiency syndrome (HIV/AIDS).

\section{Chronic pain management}

Non-malignant chronic pain is associated with physical, emotional, and financial disability. Patients with chronic pain are more likely than patients without chronic pain to utilize health care services. Patients with chronic pain report impairments of multiple quality of life measures, including physical, social, and psychological well-being. ${ }^{8}$ In addition, patients with chronic pain experience coexisting symptoms of depression or anxiety that also influence health care. ${ }^{6}$ This mixture of physical, emotional, and social abnormalities often complicates the management of patients with chronic pain. Treatment of chronic pain needs to address the physical pathology that initiated the chronic pain, as well as the important social and psychological sequelae of chronic symptoms. The goals of chronic pain management, therefore, should include reconditioning, reducing pain, and improving function, sleep, and mood. Although pain is rarely eliminated, treatment should be aimed at reducing daily pain levels, as well as the frequency, severity, and duration of pain flares. Treatment regimens generally involve a multidisciplinary approach utilizing education and medication together with physical, occupational, and behavioral therapy. It needs to be understood that pain has a physiologic basis, improved function is essential to decreased pain, and that chronic pain may not entirely resolve.

The WHO analgesic ladder ${ }^{15}$ provides a framework that health care providers can use when developing treatment plans for patients suffering from chronic pain. The analgesic ladder proposes that Step 1 in the treatment of pain should begin with a simple, non-opioid analgesic (eg, acetaminophen or non-steroidal anti-inflammatory drugs [NSAIDs]). If pain is not adequately controlled, Step 2 calls for the introduction of a weak opioid analgesic to be considered for mild to moderate pain (eg, Tramadol or codeine). If treatment with the Step 2 analgesic is not sufficient, Step 3 advises that a stronger opioid may be introduced into the management regimen (eg, 
morphine, fentanyl). The analgesic ladder also includes the possibility of adding adjuvant treatments for neuropathic pain or for symptoms associated with cancer. Figure 1 presents the schema for the analgesic pain treatment ladder.

Although NSAIDs may be helpful with pain flares, it is recommended in most cases that they should not be used chronically on a daily basis given their associated significant side effects, including end-stage renal disease in two out of every 1,000 patients who use them daily for 5 years or more. ${ }^{16,17}$ The use of analgesic combination products is also associated with significant side effects. Chronic use of NSAIDS, aspirin, or acetaminophen is found be associated with hepatotoxicity, coagulopathy, end-stage renal disease, and death. ${ }^{16,17}$ Ulcer formation occurs in $2 \%-4 \%$ of chronic NSAID users every year. ${ }^{16,18}$ NSAIDs have also been associated with reducing the effectiveness of some antihypertensives (beta-blockers, angiotensin-converting enzyme inhibitors, and diuretics) and increasing the effect of sulfonylureas when used in conjunction with these drugs. These effects are generally prostaglandin-mediated and therefore not seen with Tramadol or opioids..$^{19,20}$

\section{Materials and methods}

The focus of this article is to review the attributes of the four once-daily extended-release formulations of Tramadol available in Canada and the United States for the management of chronic non-cancer pain. The review searched for the Tramadol formulations in the following databases, searching

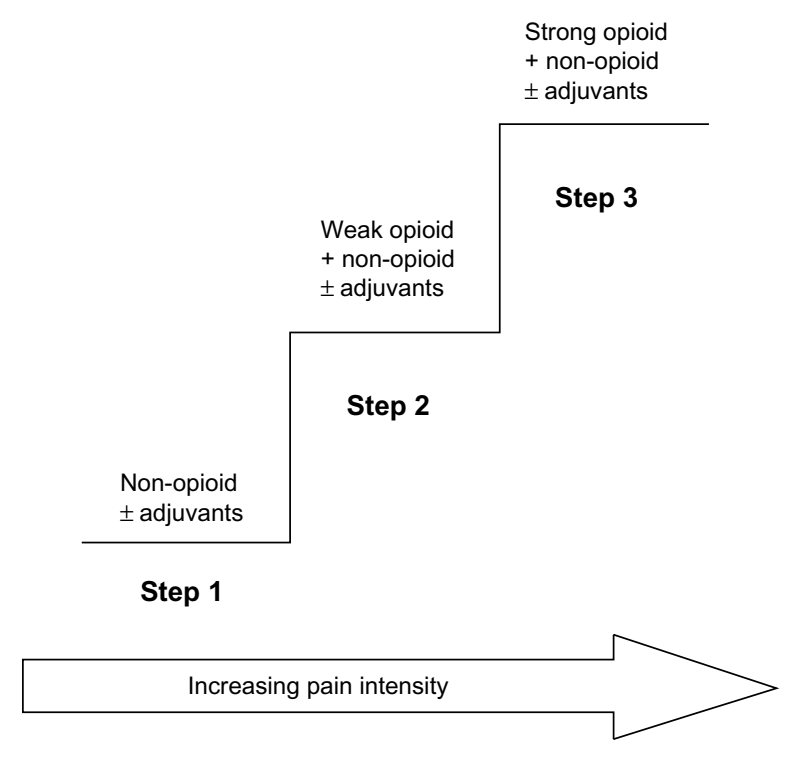

Figure I Schema of WHO 3-step analgesic ladder. Note: Data from WHO http://www.who.int/cancer/palliative/painladder/en/. Abbreviation: WHO, World Health Organization. between 1966 and January 30, 2013: International Pharmaceutical Abstracts, PubMed, Embase, Health Canada websites, United States Food and Drug Administration websites, Drug Product Monographs, company websites, and other published sources of information available.

\section{Focus on Tramadol Development history}

Tramadol was first marketed by Grünenthal GmbH. Stolberg, Germany in 1977. ${ }^{23}$ Presently, immediate, extended-release, and injectable formulations of Tramadol are available in more than 75 countries, including the USA, Canada, United Kingdom, and the People's Republic of China. ${ }^{23}$ On a worldwide level, the use of Tramadol corresponds to more than 823 million patient treatment days. This large worldwide clinical experience with both immediate-release and extended-release formulations has confirmed the efficacy of the analgesic effect of Tramadol in different painful diseases, as well as the relatively low incidence of adverse side effects. This same trend in efficacy and safety has been observed in numerous clinical trials and post-market experiences in large number of patient groups with chronic pain who were administered immediate and extended- or controlled-release Tramadol products in Canada and the United States. ${ }^{24,25}$

In Canada and the United States, the following extendedrelease or long-acting formulations of Tramadol are available in the market, shown with their year of availability: Zytram $\mathrm{XL}^{\circledR}$ (2006; Purdue Pharma, Pickering, ON, Canada), Ralivia $^{\text {TM }}$ (2007; Valeant Pharmaceuticals, Laval, QC, Canada, trade name Ultram ${ }^{\circledR}$ ER in the US), Tridural ${ }^{\circledR}(2007$; Labopharm Inc., Laval, QC, Canada), and Durela ${ }^{\circledR}$ (2012, trade name Conzip ${ }^{\mathrm{TM}}$ in US), (Cipher Pharmaceuticals Inc., Mississauga, Ontario, Canada). ${ }^{26,27}$

\section{Mode of action}

Tramadol is a synthetic 4-phenyl-piperidine analog of codeine. Although Tramadol belongs to the opioid class of drugs, its mode of action is different from other opioid drugs. Tramadol is a "weak opioid" because of its relatively low affinity for $\mu$-opioid receptors, which are the main therapeutic target for traditional opioid analgesics. ${ }^{28}$ Furthermore, the analgesic activity of Tramadol is achieved with at least two complementary mechanisms of action - binding of parent compound and its M1 metabolite (produced by liver O-demethylation) to the $\mu$-opioid receptors and weak inhibition of the reuptake of norepinephrine and serotonin. ${ }^{28-30}$ Selectivity for $\mu$-opioid receptors has been demonstrated; the M1 metabolite of Tramadol shows a higher affinity 
for opioid receptors than the parent drug. ${ }^{29}$ Nevertheless, this affinity for $\mu$-opioid receptors of the central nervous system remains low, being 6,000 times lower than that of morphine. Moreover, and in contrast to other opioids, the analgesic and antinociceptive effects of Tramadol are only partially inhibited by the opioid antagonist naloxone, which suggests the existence of another mechanism of action. This was demonstrated by the discovery of a monoaminergic activity that inhibits noradrenaline (norepinephrine) and serotonin (5-hydroxytryptamine [5-HT]) reuptake, making a significant contribution to the analgesic action by blocking nociceptive impulses at the spinal level. This multimodal mechanism of action results in Tramadol's self-synergistic activity for achieving analgesia, but not for adverse reactions. ${ }^{29}$ The recommended daily dose of immediate-release Tramadol is between $50 \mathrm{mg}$ and $100 \mathrm{mg}$ every 4 to 6 hours, with a maximum dose of $400 \mathrm{mg} /$ day. ${ }^{27}$ The half-life of immediate-release Tramadol taken orally is approximately 5-6 hours. Hence immediate-release Tramadol has to be taken several times, resulting in peaks and troughs of plasma levels of the drug. This fluctuation can lead to unpredictable pain control and an increased risk of adverse events that are associated with high peak plasma levels. Extended or controlled release formulations of Tramadol have been developed in order to deliver the drug in a more controlled and prolonged manner. ${ }^{31-33}$ However, there are technology differences between formulations which - although biologically similar - result in differences in pharmacokinetics, drug-release patterns, and availability that may influence the adverse reaction profile between formulations. ${ }^{34}$

An ideal formulation of an analgesic for chronic noncancer pain management, with special reference to once-daily Tramadol, would be to provide consistent pain control over a 24-hour dosing interval, fewer sleep interruptions, better quality of life, and increased compliance and convenience because of a simplified dosing regimen (including minimal dependence on being taken with or without meals), as well as a minimization of adverse events associated with peak drug levels. For the purposes of this review, four different formulations of once-daily extended or controlled release Tramadol are considered.

\section{Opioid treatment and Tramadol}

The National Pain Centre of Canada guidelines for safe and effective use of opioids for chronic non-cancer pain have made recommendations for physicians deciding to initiate opioid therapy in patients; the Canadian Guideline for Safe and Effective Use of Opioids for Chronic Non-Cancer Pain has been available since $2010 .{ }^{35}$ Recommendations in the guidelines state that before initiating opioid therapy, comprehensive documentation should be made on the patient's pain and general medical condition, as well as their psychosocial history, psychiatric status, and substance use history. It also recommends that physicians use screening tools such as the Opioid Risk Tool (ORT; National Pain Centre, McMaster University, Ontario, Canada) (accessible at http://nationalpaincentre.mcmaster.ca/ opioid/cgop b app b02.html) to help determine a patient's risk for opioid addiction; additionally, before initiating opioid therapy, evidence related to effectiveness in patients with chronic non-cancer pain should be considered. The American Pain Society guidelines (2009) recommend Tramadol in any phase of osteoarthritis as a single therapy or in a combination with acetaminophen or NSAIDs. ${ }^{36}$ Similarly, the American College of Rheumatology guidelines (2012) on the management of osteoarthritis recommends Tramadol in patients for whom acetaminophen, NSAIDs, and COX-2 inhibitors are no longer effective. ${ }^{37}$ The use of strong opioid analgesics for long-term management of chronic non-cancer pain is accepted, although it is still debated in medical practice. ${ }^{4}$ They should be prescribed as part of a multimodal treatment plan, with the aim of pain relief and to facilitate rehabilitation. ${ }^{37,38}$

\section{Formulation profiles}

Table 1 shows a summary profile of the four major once-daily, extended- and controlled-release Tramadol formulations approved in Canada and the United States. ${ }^{26,27}$

Table I Tramadol extended or controlled release formulations available in Canada/United States (as of November 20I3)

\begin{tabular}{lllll}
\hline & Zytram XL $^{\circledR}$ & Ralivia $^{\text {TM}} /$ Ultram $^{\circledR}$ ER & Tridural $^{\circledR}$ & Durela $^{\circledR}$ \\
\hline Distributor & Purdue & Valeant & Paladin & Medical Futures Inc. \\
Manufacturer & Purdue & Valeant/PriCara-Janssen & Labopharm & Cipher \\
Formulation & Extended-release & Extended-release & Controlled release & Extended-release \\
& 24 hours & 24 hours & 24 hours & 24 hours \\
Dose strength & $75 \mathrm{mg}, 100 \mathrm{mg}, 150 \mathrm{mg}$, & $100 \mathrm{mg}, 200 \mathrm{mg}$ and & $100 \mathrm{mg}, 200 \mathrm{mg}$ and & $100 \mathrm{mg}, 200 \mathrm{mg}$ \\
available & $200 \mathrm{mg}, 300 \mathrm{mg}$ and $400 \mathrm{mg}$ & $300 \mathrm{mg}$ & $300 \mathrm{mg}$ & and $300 \mathrm{mg}$ \\
Max dose & $400 \mathrm{mg}$ & $300 \mathrm{mg}$ & $300 \mathrm{mg}$ & $300 \mathrm{mg}$ \\
\hline
\end{tabular}

Note: Zytram XL ${ }^{\oplus}$ (Purdue Pharma, Pickering, ON, Canada); Ralivia ${ }^{\top M}$ (Valeant Pharmaceuticals, Laval, QC, Canada, trade name Ultram ${ }^{\oplus}$ ER in the US); Tridural $^{\circledR}($ Labopharm Inc., Laval, QC, Canada); and Durela ${ }^{\circledR}$ (trade name Conzip ${ }^{\mathrm{TM}}$ in US), Cipher Pharmaceuticals Inc., Mississauga, Ontario, Canada. 


\section{Zytram XL}

Zytram XL, manufactured and marketed by Purdue Pharma Inc., (Pickering, ON, Canada), is available as $75 \mathrm{mg}, 100 \mathrm{mg}$, $150 \mathrm{mg}, 200 \mathrm{mg}, 300 \mathrm{mg}$, and $400 \mathrm{mg}$ controlled-release tablets. The published pharmacokinetic profile of the drug shows that following oral administration of one Zytram XL $200 \mathrm{mg}$ tablet in the fasting state, the mean peak plasma concentration $\left(\mathrm{C}_{\max }\right)$ was $34 \%$ (dose adjusted) to that of a $100 \mathrm{mg}$ dose of Tramadol given as an oral solution. ${ }^{39}$ This was associated with a more prolonged time after administration when the maximum plasma concentration is reached $\left(\mathrm{T}_{\max }\right)$ (median 6 hours; range 4-8 hours) compared with the oral solution (median 1.5 hours; range $0.75-4$ hours). The extent of absorption of Tramadol from the Zytram XL $200 \mathrm{mg}$ tablet was equivalent to that of the $100 \mathrm{mg}$ immediate-release Tramadol solution, after dose adjustment. ${ }^{39}$ With respect to taking the drug with or without food, the monograph states that in the presence of food, the bioavailability and controlled release properties of Zytram XL tablets are maintained, with no evidence of dose-dumping. ${ }^{39}$ The elimination half-life of Tramadol is approximately 6 hours, although this is extended to around 16 hours as a result of prolonged absorption from the Zytram XL tablets. ${ }^{39}$

With respect to the dose-proportionality of different strengths of Zytram XL, in a single dose study the doseadjusted bioavailability of the $200 \mathrm{mg}, 300 \mathrm{mg}$, and $400 \mathrm{mg}$ tablets were equivalent, confirming a linear pharmacokinetic response with respect to both Tramadol and O-DesmethylTramadol, over the $200-400 \mathrm{mg}$ dosage strengths. In a steady state study, the dose adjusted bioavailability of the $150 \mathrm{mg}$ and $200 \mathrm{mg}$ tablets administered once daily were equivalent. The bioavailability of all strengths of Zytram XL is therefore dose-proportional. ${ }^{39}$ A steady state study also confirmed that Zytram XL $150 \mathrm{mg}$ tablets provided an equivalent peak concentration and extent of absorption of Tramadol as an immediate-release capsule $50 \mathrm{mg}$ administered every 8 hours ${ }^{39}$ Interestingly, in contrast to other extended-release Tramadol formulations, the recommended initial dose for opioid-naïve patients is $150 \mathrm{mg}$ of Zytram XL, ${ }^{39}$ instead of the usual $100 \mathrm{mg}$ every 24 hours for other formulations.

\section{Ralivia (Canada)/Ultram ER (US)}

Ralivia/Ultram ER (Valeant Pharmaceuticals, Laval, QC, Canada) are available as $100 \mathrm{mg}, 200 \mathrm{mg}$, and $300 \mathrm{mg}$ tablets. Ralivia/Ultram ER tablets are manufactured using a novel polymer diffusion-based film technology and a semi-permeable coating composed of water-insoluble but water-permeable film-forming polymer, plasticizer, and water-soluble polymer. The pharmacokinetic profile of the drug describes the presence of a lag time in drug absorption following the administration ${ }^{40}$ of Ralivia/Ultram ER. The mean $\mathrm{C}_{\max }$ of the parent compound Tramadol and the principal metabolite (M1) following administration of Ralivia/ Ultram ER tablets to healthy volunteers are attained at about 12 hours and 15 hours respectively, after dosing and steadystate plasma concentrations of both Tramadol and M1 are achieved within 4 days with once-daily dosing. The mean terminal plasma elimination half-lives of racemic Tramadol and racemic M1 after administration of Ralivia/Ultram ER are approximately 7.9 and 8.8 hours, ${ }^{40}$ respectively. The reported pharmacokinetics of Ralivia/Ultram ER are approximately dose-proportional over a $100-400 \mathrm{mg}$ dose range" in healthy subjects..$^{33,40}$

With reference to taking Ralivia/Ultram ER with food, available information reveals that Ralivia/Ultram ER may be taken without regard to food and that it simply be taken in a consistent manner. ${ }^{40}$ In a reported pharmacokinetic study after a single dose administration of a Ralivia/Ultram ER $200 \mathrm{mg}$ tablet with a high fat meal, the $\mathrm{C}_{\max }$ decreased by $28 \%$ and the area under curve (AUC) ${ }_{0 \text {-inf }}$ decreased by $14 \%$ respectively, compared to fasting conditions. ${ }^{40} \mathrm{~A}$ similar observation is made with respect to the $\mathrm{T}_{\text {max }}$, where it is noted to be increased by 3 hours, from 14 hours under fasting conditions, to 17 hours under fed conditions. Reported studies of Ralivia/Ultram ER have not demonstrated a clinical benefit at a total daily dose exceeding $300 \mathrm{mg} \cdot{ }^{33,40}$

\section{Tridural (Canada)}

Tridural extended-release tablets, manufactured by Paladin Labs, Inc., (Sait-Laurent, QC, Canada), are available as $100 \mathrm{mg}, 200 \mathrm{mg}$, and $300 \mathrm{mg}$ extended-release tablets. Tridural tablets are comprised of a dual-matrix delivery system with an outer compression coat (containing Tramadol hydrochloride) providing immediate-release characteristics and a controlled-release core containing Tramadol hydrochloride and Contramid ${ }^{\circledR}$, which provides controlled-release characteristics. ${ }^{41}$

The pharmacokinetic profile of Tridural extended-release tablets describes the absence of any lag time in drug absorption following oral administration. ${ }^{41}$ Tridural tablets exhibit a plasma concentration versus time profile with a sharp initial slope similar to immediate-release tablets, followed by a sustained release phase. This behavior of Tridural has been attributed to the two phases of drug release from the extended-release tablets. Dose proportionality of Tridural $100 \mathrm{mg}, 200 \mathrm{mg}$, and $300 \mathrm{mg}$ tablets has been demonstrated 
in single dose studies. Data from a steady-state study with Tridural $200 \mathrm{mg}$ extended-release tablets showed that steady state levels were reached within 48 hours following multiple dose administration. ${ }^{41}$

With respect to the administration of Tridural extendedrelease tablets with or without food, it has been reported that coadministration with food did not significantly change the overall exposure to Tramadol; ${ }^{41}$ however, it was observed that $\mathrm{C}_{\max }$ increased. Administration of Tridural with a high fat meal does not significantly affect AUC; however, $\mathrm{C}_{\max }$ increased $67 \%$ following administration of a single $300 \mathrm{mg}$ tablet and 54\% following administration of a single $200 \mathrm{mg}$ tablet. ${ }^{42}$ In all efficacy and safety studies of the drug, Tridural was administered either with breakfast or before breakfast. The dosing recommendation for Tridural tablets is that it should be taken once a day at breakfast. ${ }^{41,42}$

\section{Durela $^{\circledR}$ (Canada)/ConZip ${ }^{\text {TM }}$ (US)}

Durela $^{\circledR}$ (CIP-Tramadol), manufactured by Cipher Pharmaceuticals Inc. (Mississauga, Ontario, Canada), is available as $100 \mathrm{mg}, 200 \mathrm{mg}$, and $300 \mathrm{mg}$ extended-release capsules in Canada and the US. The Durela manufacturing technology is novel and unique. The Durela capsules are comprised of an immediate-release tablet and multiple extended-release beads. The extended-release beads consist of a Tramadol core covered with a microporous polymer membrane. All beads are similar and each of them may be considered an individual controlled release system. As the Durela capsule dissolves in the stomach, water crosses the membrane and penetrates into the beads. The water then dissolves a fraction of the Tramadol content and the solute is released from the bead into the gut by osmotic pressure. As this process continues, Tramadol is progressively released at a constant rate until the bead core is depleted of its Tramadol content (Figure 2). ${ }^{43}$ The microporous insoluble membrane properties are not affected by the gastrointestinal environment, eg, $\mathrm{pH}$, amount of water, fat content, or peristaltic motility of the gastrointestinal tract (Figure 3). This effect is the mechanism that gives Durela its independence from food effect. "All strengths of Durela capsules have been reported to be dose proportional over the 100-300 mg range". ${ }^{31,43}$ The pharmacokinetic profile describes the presence of a dual mode of action with Durela extended-release capsules. The immediate-release component in Durela capsules provides

\section{CIP-Tramadol proprietary architecture \\ Combining immediate-release and extended-release bead components}

Immediate-release tablet provides rapid release of Tramadol similar to other immediate-release Tramadol formulations. Extended-release beads form an osmotic pressure-driven release system that allows a continuous release of Tramadol over a 24-hour dosing cycle.

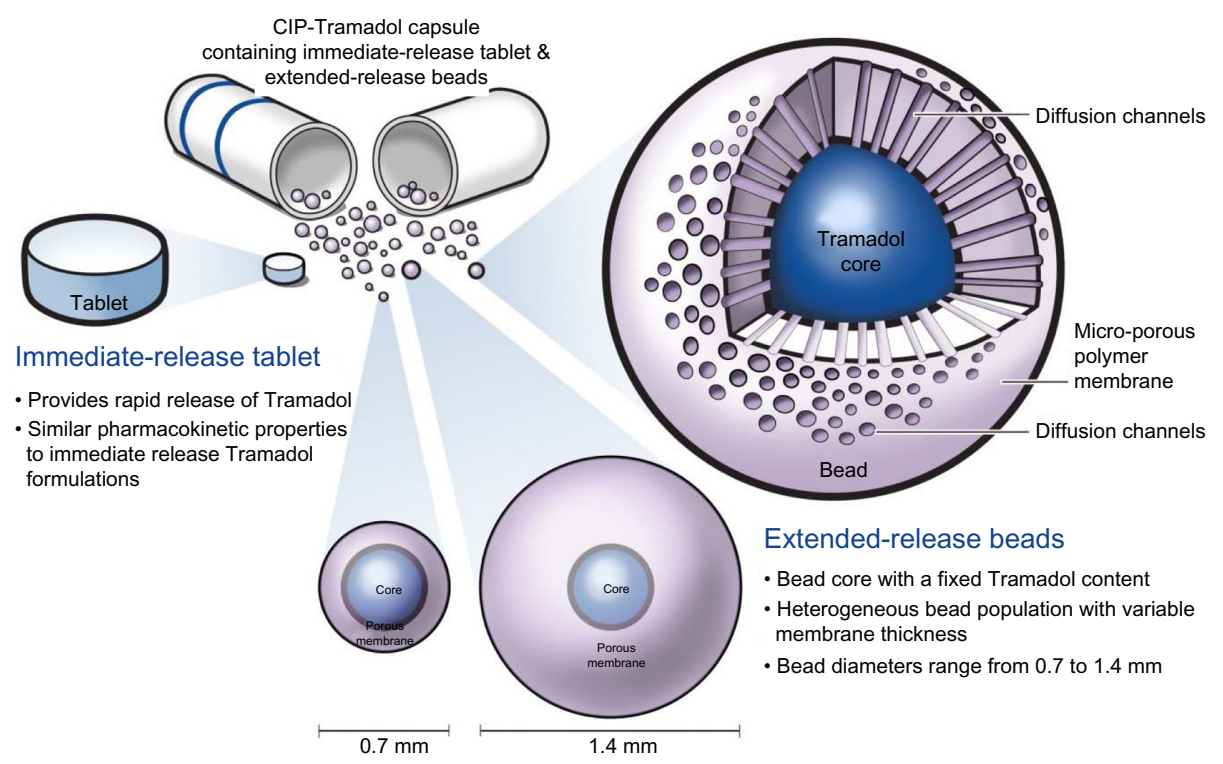

Figure 2 CIP-Tramadol proprietary delivery architecture.

Note: Figure and pharmacokinetic data reproduced with permission from Cipher Pharmaceuticals Inc. 
the same onset of analgesia as seen with immediate-release Tramadol products. This is followed by the extended-release component of the capsules which provides a consistent release of Tramadol throughout the 24-hour dosing cycle. In one single-dose study comparing Durela (CIP-Tramadol ER)
$300 \mathrm{mg}$ capsules versus $300 \mathrm{mg}$ of a marketed formulation of extended-release Tramadol, Durela $\mathrm{C}_{\max }$ were above $110 \mathrm{ng} / \mathrm{mL}$ at 1 hour post-dosing and above $191 \mathrm{ng} / \mathrm{mL}$ at the end of 24 hours post-dose. The half-life of Durela has been reported to be approximately 9 hours. ${ }^{31,43}$

\section{Combined delivery mechanisms of CIP-Tramadol}

Immediate and extended release components provide consistent delivery of Tramadol

throughout a 24-hour dosing cycle Immediate release tablet allows initial delivery of Tramadol within 1 hour.

Osmotic pressure drives the dissolved Tramadol out of the extended release beads and into the surround environment over time.

This combined delivery mechanism is not affected by $\mathrm{pH}$, osmolarity, lipid content or peristaltic motility of the $\mathrm{Gl}$ tract.
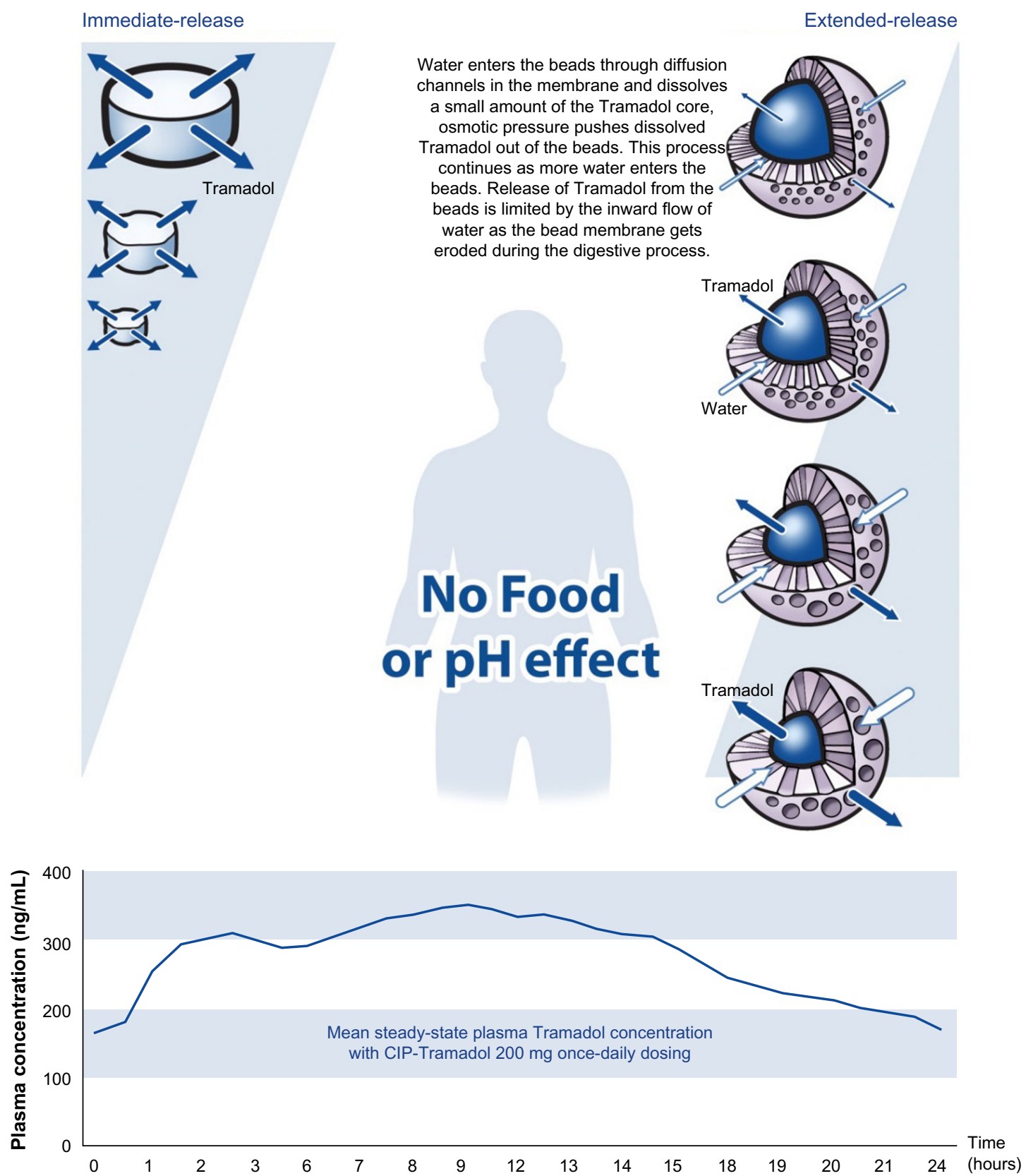

Figure 3 Combined delivery mechanisms of CIP-Tramadol in the gastrointestinal tract.

Note: Pharmacokinetic data obtained from Durela ${ }^{\circledR}$ Health Canada product monograph (20II). Figure and pharmacokinetic data reproduced with permission from Cipher Pharmaceuticals Inc. 
To review the effect of taking Durela with or without food, a single dose study with Durela $300 \mathrm{mg}$ capsules reported that based on the pharmacokinetic analysis of Tramadol and the M1 metabolite, Durela (CIP-Tramadol) $300 \mathrm{mg}$ extendedrelease capsules showed bioequivalence with respect to the rate $\left(\mathrm{C}_{\max }\right)$ and extent (AUC) of absorption. ${ }^{44}$ The reported conclusion was that Durela capsules can be administered without regard to meals. ${ }^{31}$ In another single dose study comparing the effect of taking Durela under fed or fasting conditions, the study results demonstrated the presence of bioequivalence of the drug under both fed as well as fasting states, demonstrating the absence of food effect with Durela. Figure 4 presents the results of the single-dose food effect study following administration of Durela $300 \mathrm{mg}$ capsules dosed under fed or fasting conditions. ${ }^{31,43,44}$

\section{Discussion}

Despite progress in our knowledge of the pathophysiology of pain, the management of chronic non-cancer pain continues to challenge physicians ${ }^{47}$ Contemporary, standard pharmacotherapy for the treatment of chronic non-cancer pain includes the use of opioid medication. The aim of opioid medications should be to relieve pain and improve functional capacity and quality of life. Evidence from published literature including the results from controlled clinical trials indicates that opioid medications can relieve pain in a variety of pain syndromes. ${ }^{24,25,46}$

A number of drugs have proven to be effective in chronic pain disorders and their use individually or in combination should improve the management of chronic pain. Patients with chronic pain require medications that are able to provide adequate pain relief and have minimum dosing intervals to maintain efficacy, as short dosing intervals carry the risk of breakthrough pain.

Ideally, drugs prescribed for the management of chronic pain should have the attributes of fast or rapid onset and consistent absorption, as well as significant plasma levels at the end of the dosing interval to be able to provide adequate pain relief. Convenience of dosing, ie, having to take the drug with or without meals or certain types of food, may become a burden for patients if they have to take the medication for an indefinite period of time.

Tramadol has been available in the international marketplace for more than 4 decades. Based on experience from numerous clinical studies as well as global post-marketing experience, the efficacy and safety profile of both immediate- and extended-release Tramadol makes it a suitable drug as a long-term treatment for a variety of chronic noncancer pain syndromes. ${ }^{25,46}$ Results from several controlled clinical studies have shown that the efficacy of once-daily or extended-release formulations of Tramadol is similar to other Tramadol formulations for the management of chronic non-cancer pain..$^{38,46-50}$ The extended-release or controlledrelease formulations of Tramadol allow patients to maintain an acceptable level of analgesia following the administration of a single daily dose. ${ }^{50,51}$

From the safety perspective, data have shown that issues related to drug dependence and tolerance with

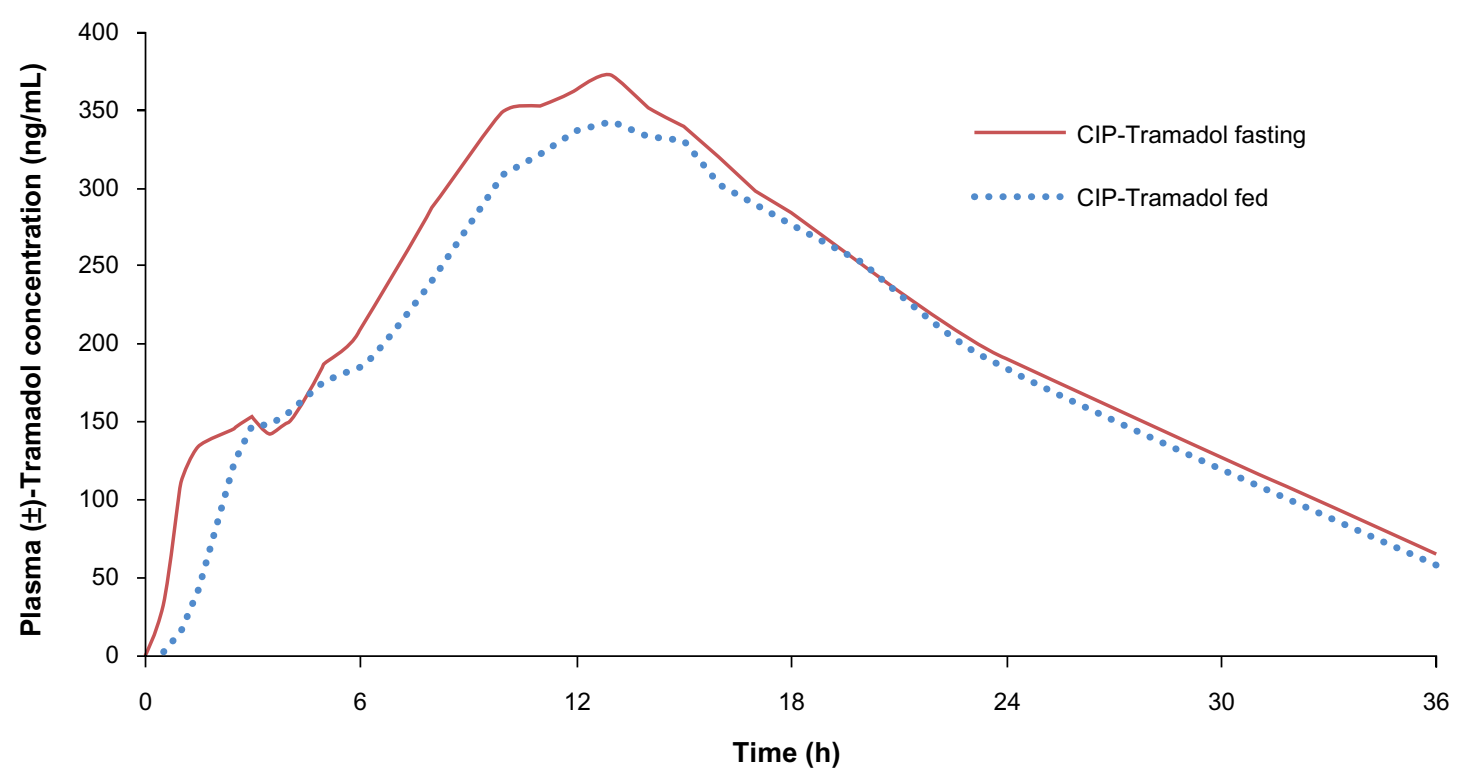

Figure 4 Plasma $( \pm)$-Tramadol concentrations $(\mathrm{ng} / \mathrm{mL})$ following a single-dose oral administration of CIP-Tramadol ER capsules (300 mg). Note: Figure and pharmacokinetic data reproduced with permission from Cipher Pharmaceuticals Inc. 
extended-release Tramadol do not pose a potential safety concern for the patients. ${ }^{43}$ Contraindications to the use of all formulations of immediate- and extended-release Tramadol have been reported to be similar to other opioid compounds. Major contraindications include hypersensitivity to Tramadol and opioids, gastrointestinal obstruction, intoxication with alcohol and hypnotics, concomitant use of central nervous system depressants, psychotropic drugs, monoamine oxidase inhibitors, patients with severe hepatic or renal impairment, acute asthma, airway obstruction, status asthmaticus, and acute respiratory depression. . $^{27,31-33,39-42}$

During recent years some opioids have been associated with prolonged QT and torsade de pointes (TdP). In vitro testing has shown that most opioids can block the cardiac potassium channels. This indicates that QT prolongation and TdP could be a more general problem associated with the use of these drugs. However, reports from published literature show that Tramadol use at therapeutic levels has not been associated with QT prolongation. ${ }^{53}$

Review of information has shown that the major Tramadol extended-release formulations available in Canada and the United States - namely Zytram XL, Ralivia/Ultram ER, Tridu$\mathrm{ral}$, and Durela/ConZip - have all been individually reported to possess similar efficacy and safety profiles. However, despite a shared or nearly similar mechanism of action, general differences in pharmacokinetic profiles amongst the formulations differentiate some of the products more than others, which may also translate into varied clinical responses within the same patient populations. Selection of the most appropriate extended-release Tramadol formulation should therefore be based on the patient's individual needs, and lifestyles should be taken into account in the treatment program by health care provider. Some of the points to consider in making a decision about the appropriate treatment option for extended-release Tramadol should be: 1) fast onset of action, ie, the ability to reach the level for effective therapeutic analgesia within the dosing interval; 2) at steady state, the formulation should ensure adequate plasma concentration shortly after dosing and should maintain therapeutic levels throughout the 24-hour dosing cycle, thereby minimizing the risk of breakthrough pain and side effects; and 3) the pharmacokinetic profile of an ideal extended-release Tramadol formulation should not be influenced by taking the drug with or without meals.

Table 2 presents a comparison of the mean steady-state plasma concentrations of Tramadol following the once daily administration of $200 \mathrm{mg}$ of the extended/controlled-release formulation. Comparative data from studies were not available for Zytram XL and Ralivia. A review of the available information
Table 2 Mean steady-state plasma concentrations of Tramadol following the once-daily administration of $200 \mathrm{mg}$ of the formulation

\begin{tabular}{lllll}
\hline Parameter & Zytram $\mathbf{X L}^{\circledR}$ & Ultram $^{\circledR}$ ER & Tridural $^{\circledR}$ & Durela $^{\circledR}$ \\
\hline $\mathrm{AUC}_{0-24}(\mathrm{ng} / \mathrm{mL})$ & $\mathrm{NA}$ & 5,975 & $5,99 \mathrm{I}$ & 6,600 \\
$\mathrm{C}_{\text {max }}(\mathrm{ng} / \mathrm{mL})$ & $\mathrm{NA}$ & 335 & 345 & 364 \\
$\mathrm{C}_{\text {min }}$ (ng/mL) & NA & 187 & 157 & 165 \\
$\mathrm{~T}_{\text {max }}$ (hour) & NA & 12 & 4.0 & 9.7 \\
\hline
\end{tabular}

Note: Zytram XL ${ }^{\circledR}$ (Purdue Pharma, Pickering, ON, Canada); Ralivia ${ }^{\top M}$ (Valeant Pharmaceuticals, Laval, QC, Canada, trade name Ultram ${ }^{\circledast}$ ER in the US); Tridural ${ }^{\circledast}$ (Labopharm Inc., Laval, QC, Canada); and Durela ${ }^{\circledR}$ (trade name Conzip ${ }^{\mathrm{TM}}$ in US), Cipher Pharmaceuticals Inc., Mississauga, Ontario, Canada.

Abbreviations: $A \cup C_{0-24}$, area under curve; $C_{\text {max }}$, peak plasma concentration; $C_{\text {min' }}$, minimum plasma concentration; $\mathrm{T}_{\text {max }}$, time to maximum concentration.

for Tridural showed that in one single-dose study with Tridural $200 \mathrm{mg}$ extended-release tablets, the plasma concentration of Tramadol following 1 hour and 24 hours post-dose was observed to be approximately $80 \mathrm{ng} / \mathrm{mL}$ and $100 \mathrm{ng} / \mathrm{mL}$, respectively. Available data for plasma concentrations from a similar comparable single-dose study of Durela 200 mg extended-release capsules were observed to be above $100 \mathrm{ng} / \mathrm{mL}$ within 1 hour post-dosing and above $117 \mathrm{ng} / \mathrm{mL}$ after 24 hours. As reported in published literature, Tramadol plasma concentration of $100 \mathrm{ng} / \mathrm{mL}$ has been associated with the onset of perceptible analgesia. ${ }^{54}$ In a steady-state study with Tridural $200 \mathrm{mg}$ tablets, the mean $\mathrm{C}_{\min }$ value for Tramadol was reported to be $157 \mathrm{ng} / \mathrm{mL}$; in a similar steady-state study with Durela $200 \mathrm{mg}$ extended-release capsules, the $\mathrm{C}_{\min }$ value for Tramadol was reported to be $165 \mathrm{ng} / \mathrm{mL}$. In steady-state studies, at the end of 24 hours, plasma concentration of Tridural was observed to be approximately in the $100-120 \mathrm{ng} / \mathrm{mL}$ range. Observations for Durela $200 \mathrm{mg}$ in steady-state studies showed plasma concentration in the 150-200 $\mathrm{ng} / \mathrm{mL}$ range (Figure 5). Based on the review of the available information, it was observed that Durela seems to possess a number of attributes in its pharmacokinetic profile that significantly differentiates it from the other extended-release Tramadol formulations. Based on available information, the general efficacy and safety profile of all the Tramadol extended-release formulations has been reported to be similar. In this review, Durela is noted to be one of the few truly once-daily-dosing extended-release Tramadol formulations currently on the market, as demonstrated by its fast onset of action; this is based on the presence of a significant immediate-release component, similar to that of immediate-release Tramadol. The release of the drug from the immediate-release component in Durela is followed by its consistent plasma levels throughout the 24-hour dosing interval and the ability to maintain significant plasma levels at the end of 24 hours, differentiating it from other Tramadol extended-release formulations. This aspect of Durela may help 


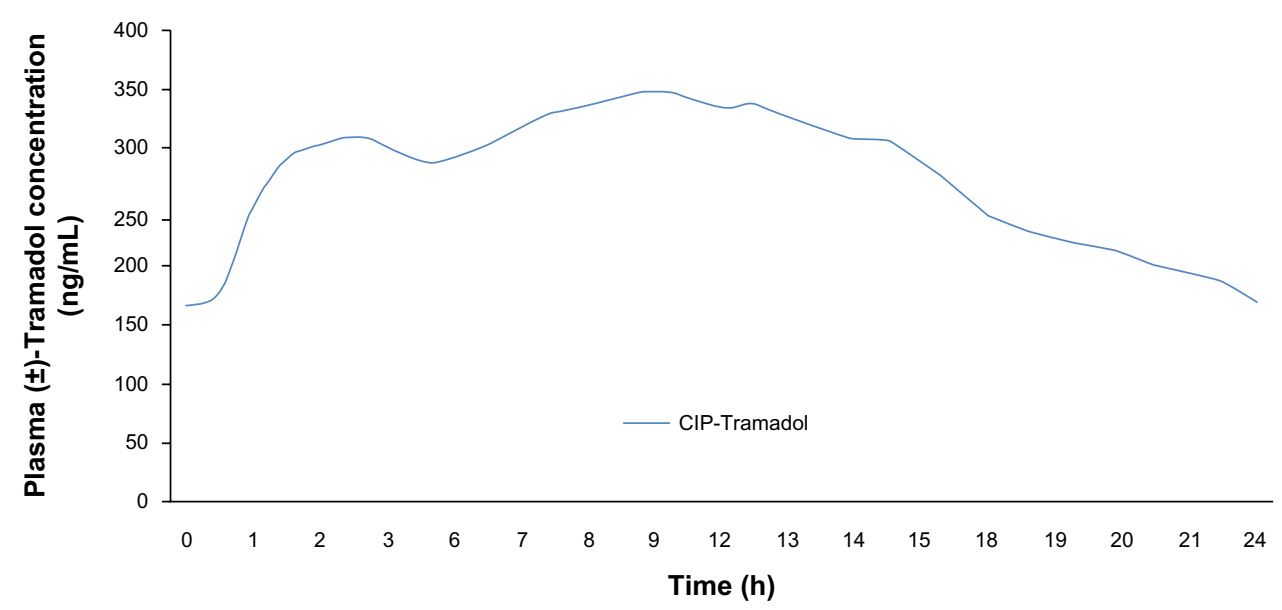

Figure 5 Mean steady-state Tramadol plasma concentration of CIP-Tramadol ER capsules 200 mg once daily. Note: Figure and pharmacokinetic data reproduced with permission from Cipher Pharmaceuticals Inc.

in providing the chronic pain patient with adequate plasma concentrations of Tramadol throughout the 24-hour dosing cycle, as well as minimizing the risk of breakthrough pain and side effects.

One of the key aspects in relation to minimizing the incidence of side effects for all of the Tramadol extended-release formulations is to titrate the drug slowly to the next higher dose. It has been reported in published literature that a low initial dose and slow upward titration assist in minimizing adverse events; ${ }^{35,52}$ hence a 5-7 day titration period would theoretically be an effective strategy to reduce adverse events in comparison to having a relatively short titration (2-3 day) or no titration at all for patients.

Comparing the once daily extended-release/controlledrelease Tramadol formulations, Durela is noted to offer flexibility of dosing with reference to the drug being taken with or without food; it can therefore be taken at any time during the day. ${ }^{31}$ The dosing flexibility of Durela allows patients to take the medication or schedule their drug dosing not with reference to when they take meals, but when the patient needs it most, in relation to their pain control.

In comparing Durela to be dosed with or out food, the pharmacokinetic profile exhibited by another Tramadol formulation, Ralivia/Ultram ER, shows a marked difference between fed and fasted states. Ralivia/Ultram ER is shown to have a reduced $\mathrm{C}_{\max }$ under the influence of a high fat meal (Figure 6). ${ }^{33,44}$ In contrast, Tridural (Ryzolt) appears to exhibit the opposite effect, with $\mathrm{C}_{\max }$ increasing $67 \%$ following administration of a single $300 \mathrm{mg}$ tablet and 54\% following administration of a single 200 mg tablet. ${ }^{42}$ With reference to interchangeability

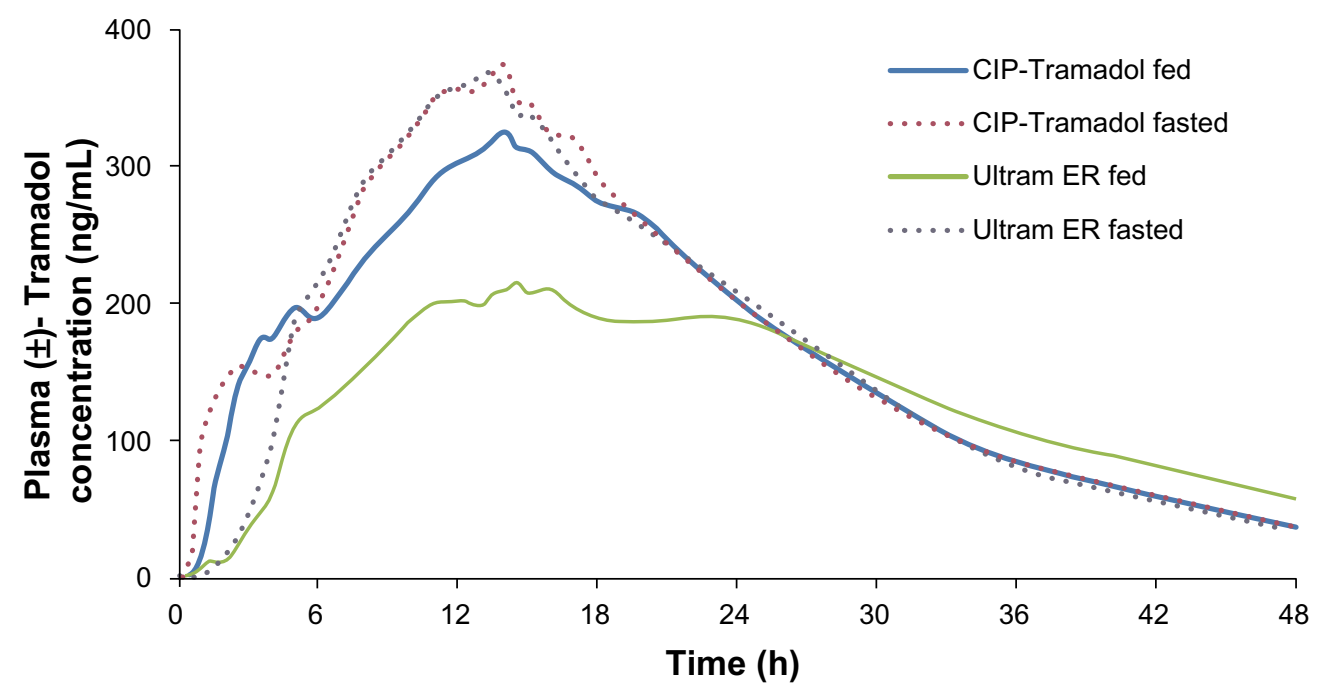

Figure 6 Pharmacokinetic comparison of CIP-Tramadol and Ultram ER under fed and fasted conditions. Note: Figure and pharmacokinetic data reproduced with permission from Cipher Pharmaceuticals Inc. 
of the Tramadol formulations, since no direct head to head studies have been conducted and due to differences in the pharmacokinetic properties amongst the formulations, which may translate into varied clinical responses for the patient, it has been reported that the extended-release Tramadol formulations are not interchangeable drug products. ${ }^{27,31-33,39-42}$

\section{Conclusion}

The review of available literature for the current extendedrelease/controlled-release formulations of Tramadol shows that all of them possess similar efficacy and safety. This has been demonstrated historically from published clinical studies as well as global post-marketing experience spanning a number of decades. General differences in the pharmacokinetic profile amongst the formulations may translate into important and varied clinical responses in patients. Selection of the appropriate formulation by the health care provider should therefore be based on the patient's chronic pain condition, needs, and lifestyle.

\section{Acknowledgments}

The authors acknowledge the financial support provided by Medical Futures Inc. (Richmond Hill, Ontario, Canada), in the preparation of this manuscript. Proprietary data relating to CIP-Tramadol was provided by Cipher Pharmaceuticals Inc. The authors would also like to acknowledge Evelyn Yu for her assistance in reviewing the manuscript.

\section{Disclosure}

The authors would like to declare the following competing interests: AK has received honoraria and or sponsorships from Hilal Pharmaceuticals; CNM has received honorarium and/or sponsorships from the following companies: Purdue Pharma, Janssen Ortho Inc., Medical Futures Inc., Valeant, Paladin, and Pfizer.

The description of the characteristics of drug products in this manuscript with special reference to the pharmacokinetics section have been quoted from the individual drug product monographs verbatim. This approach was taken because there is limited information available in published literature regarding the description of individual drugs and to avoid misinterpretation of the pharmacokinetic data, as well as other relevant information.

\section{References}

1. Pain: Hope Through Research [webpage on the Internet]. Bethesda: National Institute of Neurological Disorders and Stroke; 2009. Available from: http://www.ninds.nih.gov/disorders/chronic_pain/detail_chronic_ pain.htm\#215763084. Accessed September 17, 2013.
2. Assessment and Management of Chronic Pain [webpage on the Internet] Bloomington: Institute for Clinical Systems Improvement (ICSI); 2011. Available from: http://www.guideline.gov/content.aspx?id=36064\&sea rch=chronic+pain. Accessed September 17, 2013.

3. Trescot AM, Helm S, Hansen H, et al. Opioids in the management of chronic non-cancer pain: an update of American Society of the Interventional Pain Physicians' (ASIPP) Guidelines. Pain Physician. 2008;11(2):S5-S62.

4. Furlan AD, Sandoval JA, Mailis-Gagnon A, Tunks E. Opioids for chronic noncancer pain: a meta-analysis of effectiveness and side effects. CMAJ. 2006;174(11):1589-1594.

5. Dominick CH, Blyth FM, Nicholas MK. Unpacking the burden: understanding the relationships between chronic pain and comorbidity in the general population. Pain. 2012;153(2):293-304.

6. Goldberg DS, McGee SJ. Pain as a global public health priority. $B M C$ Public Health. 2011;11:770.

7. Canadian Pain Society [webpage on the Internet]. Pain in Canada Fact Sheet 2011. Available from: www.canadianpaincoalition.ca/media/canadian_pain_fact_sheet_22_10_10_en.pdf. Accessed September 17, 2013.

8. Tsang A, Von Korff M, Lee S, et al. Common chronic pain conditions in developed and developing countries: gender and age differences and comorbidity with depression-anxiety disorders. $J$ Pain. 2008;9(10):883-891.

9. Reitsma ML, Tranmer JE, Buchanan DM, Vandenkerkhof EG. The prevalence of chronic pain and pain-related interference in the Canadian population from 1994 to 2008. Chronic Dis Inj Can. 2011;31(4):157-164.

10. Lynch ME, Watson CP. The pharmacotherapy of chronic pain: a review. Pain Res Manag. 2006;11(1):11-38.

11. Barkin RL, Barkin SJ, Barkin DS. Pharmacotherapeutic management of pain with a focus directed at the geriatric patient. Rheum Dis Clin North Am. 2007;33(1):1-31.

12. Boulanger A, Clark AJ, Squire P, Cui E, Horbay GL. Chronic pain in Canada: have we improved our management of chronic noncancer pain? Pain Res Manag. 2007;12(1):39-47.

13. Committee on Advancing Pain Research, Care, and Education; Institute of Medicine. Relieving Pain in America: A Blueprint for Transforming Prevention, Care, Education, and Research. Washington: The National Academies Press; 2011.

14. International Association for the Study of Pain (IASP), European Federation of IASP Chapters (EFIC). Unrelieved Pain is a Major Global Healthcare Problem. Washington: International Association for the Study of Pain; 2013. Available Available from: www.iasp-pain.org/AM/ Template.cfm?Section=Press_Release $\&$ Template $=/ \mathrm{CM} /$ ContentDisplay. cfm\&ContentID=2902. Accessed September 17, 2013.

15. World Health Organization. WHO's Pain Ladder for Adults. Geneva: World Health Organization; 2014. Available from: http://www.who.int/ cancer/palliative/painladder/en/. Accessed September 17, 2013.

16. Marcus DA. Treatment of Nonmalignant Chronic Pain. Am Fam Physician. 2000;61(5):1331-1338.

17. Antman EM, Bennett JS, Daugherty A, et al. Use of nonsteroidal antiinflammatory drugs: an update for clinicians: a scientific statement from the American Heart Association. Circulation. 2007;115(12): $1634-1642$.

18. Roelofs PD, Deyo RA, Koes BW, Scholten RJ, van Tulder MW. Nonsteroidal anti-inflammatory drugs for low back pain: an updated Cochrane review. Spine (Phila Pa 1976). 2008;33(16):1766-1774.

19. Tannenbaum $\mathrm{H}$ et al. An evidence-based approach to prescribing nonsteroidal anti-inflammatory drugs. Third Canadian Consensus Conference. J Rheumatol. 2006; Jan; 33(1):140-57. Epub 2005 Dec.

20. Bhatt DL, Scheiman J, Abraham NS, et al; American College of Cardiology Foundation Task Force on Clinical Expert Consensus Documents. ACCF/ACG/AHA 2008 expert consensus document on reducing the gastrointestinal risks of antiplatelet therapy and NSAID use: a report of the American College of Cardiology Foundation Task Force on Clinical Expert Consensus Documents. Circulation. 2008; 118(18):1894-1909. 
21. Karhu D, Fradette C, Potgieter MA, Ferreira MM, Terblanché J. Comparative pharmacokinetics of a once-daily Tramadol extendedrelease tablet and an immediate-release reference product following single-dose and multiple-dose administration. J Clin Pharmacol. 2010;50(5):544-553.

22. Flick K, Frankus E. 1-(m-Substituted Phenyl)-2-Aminomethyl Cyclohexanols. 8 (1972). Available from: www.google.com/patents/ US3652589. Accessed September 13, 2013.

23. Pregolizzi JV et al. Extended-release formulations of Tramadol in the treatment of chronic pain. Expert OpinPharmacother. 2011;8;12 (11): 1757-8. dol:10.1517/14656566.2011.57620. Epub 2011 May 24.

24. Chaparro LE, Furlan AD, Deshpande A, Mailis-Gagnon A, Atlas S, Turk DC. Opioids compared to placebo or other treatments for chronic low-back pain. Cochrane Database Syst Rev. 2013;8:CD004959.

25. Schug SA. The role of Tramadol in current treatment strategies for musculoskeletal pain. Ther Clin Risk Manag. 2007;3(5):717-723.

26. Health Canada Drug Products Database [database on the Internet]. Ottawa: Health Canada. Available from: http://webprod5.hc-sc.gc.ca/ dpd-bdpp/index-eng.jsp. Accessed September 17, 2013.

27. Drugs@ FDA approved drug products [database on the Internet]. Silver Spring: Food and Drug Administration; 2006. Available from: http:// www.accessdata.fda.gov/scripts/cder/drugsatfda/. Accessed September 17, 2013.

28. Raffa R. Pharmacological aspects of successful long-term analgesia. Clin Rheumatol. 2006;25 Suppl 1:S9-S15.

29. Bamigbade TA, Davidson C, Langford RM, Stamford JA. Actions of Tramadol, its enantiomers and principal metabolite, O-desmethylTramadol, on serotonin (5-HT) efflux and uptake in the rat dorsal raphe nucleus. Br J Anaesth. 1997;79(3):352-356.

30. Hair PI, Curran MP, Keam SJ. Tramadol extended-release tablets. Drugs. 2006;66(15):2017-2027; discussion 2028-2030.

31. Durela Canadian Product Monograph [webpage on the Internet]. Mississauga; Cipher Pharmaceuticals: 2012. Available from: http:// webprod5.hc-sc.gc.ca/dpd-bdpp/info.do? code=85814\&lang=eng. Accessed September 17, 2013.

32. Cipher Pharmaceuticals. ConZip Full Prescribing Information. Mississauga; Cipher Pharmaceuticals: 2012. Available from: http:// www.verticalpharma.com/sites/vertical/files/ConZipPrescribingInfo. pdf. Accessed September 17, 2013.

33. Ultram ${ }^{\circledR}$ ER (Tramadol HCI) Extended-Release Tablets. Steinbech, MB: Valeant Pharmaceuticals International; 2012. Available from: http:// www.janssenpharmaceuticalsinc.com/assets/ultramer.pdf. Accessed September 17, 2013.

34. Langley PC, Patkar AD, Boswell KA, Benson CJ, Schein JR. Adverse event profile of Tramadol in recent clinical studies of chronic osteoarthritis pain. Curr Med Res Opin. Jan 2010;26(1):239-251.

35. Kah Kahan M, Mailis-Gagnon A, Wilson L, Srivastava A; National Opioid Use Guideline Group. Canadian guideline for safe and effective use of opioids for chronic noncancer pain: clinical summary for family physicians. Part 1: general population. Can Fam Physician. 2011;57(11):1257-1266, e407-e418.

36. Chou R, Fanciullo GJ, Fine PG, et al; American Pain Society-American Academy of Pain Medicine Opioids Guidelines Panel. Clinical guidelines for the use of chronic opioid therapy in chronic noncancer pain. J Pain. 2009;10(2):113-130.

37. Hochberg MC, Altman RD, April KT, et al; American College of Rheumatology. American College of Rheumatology 2012 recommendations for the use of nonpharmacologic and pharmacologic therapies in osteoarthritis of the hand, hip, and knee. Arthritis Care Res (Hoboken). 2012;64(4):465-474.
38. Coluzzi F, Mattia C. Chronic non-cancer pain: Focus on once-daily Tramadol formulations. Ther Clin Risk Manag. 2007;3(5):819-829.

39. Zytram XL Canadian Drug Product Monograph [webpage on the Internet]. Pickering, ON: Purdue Pharma; 2006. Available from: http:// webprod5.hc-sc.gc.ca/dpd-bdpp/info.do? $\operatorname{code}=77188 \&$ lang=eng. Accessed September 17, 2013.

40. Valeant Canada LP/Valeant Canada SEC. Ralivia Canadian Drug Product Monograph [webpage on the Internet]. Pickering, ON: Purdue Pharma; 2006. Available from: http://webprod5.hc-sc.gc.ca/dpd-bdpp/ info.do? code $=77188 \&$ lang=eng. Accessed Month DD, YYYY.

41. Paladin Labs Inc. Tridural Canadian Drug Product Monograph [webpage on the Internet]. Saint-Laurent, QC: Paladin Labs Inc.; 2007. Available from: http://webprod5.hc-sc.gc.ca/dpd-bdpp/info. do? code=78172\&lang=eng. Accessed September 17, 2013.

42. RYZOLT - Tramadol hydrochloride tablet, extended release [webpage on the Internet]. Stanford, CT: Purdue Pharma; 2011. Available from: http://app.purduepharma.com/xmlpublishing/pi.aspx?id=r. Accessed September 17, 2013.

43. Cipher Pharmaceuticals [homepage on the Internet]. Mississauga, ON; Cipher Pharmaceuticals: 2012. Available from: http://www. cipherpharma.com/. Accessed September 17, 2013.

44. Kizilbash A, Schwartz B, Mengle-Gaw L, Gross JA. Poster Abstracts 1. In Tramadol Formul Considerations Chronic Pain Manag Present 20th Annu Clin Meet l Integr Pain Manag Optim Patient Care. 52-80.

45. Woolf CJ; American College of Physicians; American Physiological Society. Pain: moving from symptom control toward mechanismspecific pharmacologic management. Ann Intern Med. 2004;140(6): 441-451.

46. Beaulieu AD, Peloso P, Bensen W, et al. A randomized, double-blind, 8 -week crossover study of once-daily controlled-release Tramadol versus immediate-release Tramadol taken as needed for chronic noncancer pain. Clin Ther. 2007;29(1):49-60.

47. McCarberg B. Tramadol extended-release in the management of chronic pain. Ther Clin Risk Manag. 2007;3(3):401-410.

48. Bodalia B, McDonald CJ, Smith KJ, O’Brien C, Cousens L. A comparison of the pharmacokinetics, clinical efficacy, and tolerability of once-daily Tramadol tablets with normal release Tramadol capsules. J Pain Symptom Manage. 2003;25(2):142-149.

49. Wilder-Smith CH, Schimke J, Osterwalder B, Senn HJ. Oral Tramadol, a mu-opioid agonist and monoamine reuptake-blocker, and morphine for strong cancer-related pain. Ann Oncol. 1994;5(2):141-146.

50. Højsted J, Sjøgren P. An update on the role of opioids in the management of chronic pain of nonmalignant origin. Curr Opin Anaesthesiol. 2007;20(5):451-455.

51. Babul N, Noveck R, Chipman H, Roth SH, Gana T, Albert K. Efficacy and safety of extended-release, once-daily Tramadol in chronic pain: a randomized 12-week clinical trial in osteoarthritis of the knee. J Pain Symptom Manage. 2004;28(1):59-71.

52. Dayer P, Desmeules J, Collart L. [Pharmacology of Tramadol]. Drugs. 1997;53 Suppl 2:18-24. French.

53. Fanoe S, Jensen GB, Sjøgren P, Korsgaard MP, Grunnet M. Oxycodone is associated with dose-dependent QTc prolongation in patients and low-affinity inhibiting of hERG activity in vitro. Br J Clin Pharmacol. 2009;67(2):172-179.

54. Malonne H, Sonet B, Streel B, et al. Pharmacokinetic evaluation of a new oral sustained release dose form of Tramadol. Br JClin Pharmacol. 2004;57(3):270-278. 
Journal of Pain Research

\section{Publish your work in this journal}

The Journal of Pain Research is an international, peer-reviewed, open access, online journal that welcomes laboratory and clinical findings in the fields of pain research and the prevention and management of pain. Original research, reviews, symposium reports, hypothesis formation and commentaries are all considered for publication.
Dovepress

The manuscript management system is completely online and includes a very quick and fair peer-review system, which is all easy to use. Visit http://www.dovepress.com/testimonials.php to read real quotes from published authors.

\footnotetext{
Submit your manuscript here: http://www.dovepress.com/journal-of-pain-research-journal
} 